\title{
Comparison of the Analgesic Effect of Low-Intensive Polarized Polychromatic Light and Analgesics
}

\author{
Sergiy A. Gulyar ${ }^{1,2}$ and Zynaida A. Tamarova ${ }^{1}$ \\ 1. Department of General Physiology of Nervous System, Bogomoletz Institute of Physiology National Academy of Sciences of
} Ukraine, Kiev 401601, Ukraine

2. International Medical Innovation Center Zepter, Kiev 02152, Ukraine

\begin{abstract}
On the model of formalin test in mice, the analgesic effects of low-intensity polarized light (PL) of BIOPTRON device (480-3,400 $\mathrm{nm}$, polarization up to $95 \%$, power density $40 \mathrm{~mW} / \mathrm{cm}^{2}$ ) and three pharmacological analgesics (ibuprofen, analgin, tramal) were compared. We used analgesics in the optimal and half-dose, as well as half-doses of analgesics combined with the application of PL to the analgesic acupuncture point (AP) E-36. Pain was induced by subcutaneous injection of a 5\% formalin solution ( $30 \mu \mathrm{L})$ into the back of the foot of the left hind limb of the animal. The intensity of pain was judged by duration of pain (licking of the affected limb) and non-painful (sleeping, eating, running, washing) behavioral reactions during 60 minutes of observation. In animals that immediately after the creation of the locus of tonic pain, received an injection (intraperitoneally) of ibuprofen, analgin or tramal in optimal doses (30.0; 8.3 and $1.7 \mathrm{mg} / \mathrm{kg}$ ), duration of the pain response reduced by $46.0 ; 74.9$ and $56.2 \%$, respectively. Half doses of these analgesics $(15.0 ; 4.2$ and $0.8 \mathrm{mg} / \mathrm{kg}$ ) weakened the pain by $23.1 ; 28.5$ and $34.2 \%$. A statistically significant reduction of pain was also observed in groups where instead of analgesics, was applied a 10-min PL session to the anti-pain AP E-36 (by $27.0 \%$ ) or to the locus of pain (by $35.8 \%$ ). These data indicate that PL analgesic effect is comparable to the effect of moderate doses of analgesics. Combined use of analgesic and PL suppresses pain more effectively than one analgesic in the same dose. The 10-minute PL application to the analgesic AP E-36 in 1.5-2 times (statistically significantly) increased the analgesic effect of small analgesics doses. In contrast to animals in which analgesia was caused by administration of high doses of analgesics, in the case of low doses of analgesic in combination with PL, caused no disturbances in motor activity and eating behavior. Clinical significance of the presented data is to prove the possibility of reducing the dose of analgesic pharmaceuticals by applying PL, which reduces the risk of unwanted side post-pharmacological effects.
\end{abstract}

Key words: Polarized light, bioptron device, pain, formalin test, analgesia, ibuprofen, analgin, tramal, acupuncture point.

\section{Introduction}

The main means to fight pain still remains chemical analgesics. Despite their effectiveness, the side effects from their use sometimes cause significant harm to health. There are known violations of hematopoiesis, liver and kidney functions, allergic reactions, drug dependence emergence $[1,2]$.

Our previous studies [3-11] showed that the low-intensity polarized light (PL) of BIOPTRON device weakens the somatic tonic (formalin test) and

Corresponding author: Sergiy Gulyar, M.D., Ph.D., D.Sc., professor, research fields: medicine (including environmental medicine), physiology, electromagnetic and light therapy (Bioptron, Laser, LED). visceral (acetate test) pain in animals, and also significantly increases the pain threshold of acute pain (electric platform). Statistically significant pain relief can be obtained by application of the PL as a specific anti pain acupuncture points (AP), and directly on the locus of pain.

The aim of the present work was to make a comparative evaluation of the analgesic effect of low-intensity PL and pharmacological analgesics, as well as to study the effects of combined use of PL and low doses of analgesics. We selected two non-narcotic analgesics widely used in the clinic (ibuprofen, analgin) and a narcotic analgesic - tramal.

The experiments were carried out on animals, this 
ensured absence of the psychological factor inevitably inherent for man, as well as the possibility to evaluate the quantity of the pain intensity.

\section{Materials and Methods}

\subsection{Animals}

The experiments were performed on adult white male mice weighing 28-32 g. All experiments were carried out in accordance with the ethical recommendations of the International Pain Association. The animals were kept in the vivarium of the Institute of Physiology, AA Bogomolets NAS of Ukraine (Kiev) in conditions of controlled temperature $\left(18-20{ }^{\circ} \mathrm{C}\right)$ and 12-hour light day. All animals had free access to water and food (special granulated food). The day before the experiment, the mice were placed one by one in plastic cells and adapted to the experimental conditions.

Animals were randomly divided into 13 groups: one control/placebo (15 mice) and 12 experimental (10 mice in a group). Immediately after the locus of inflammation creation, which was the source of prolonged tonic pain, some animals received an injection (intraperitoneally) of one of the pharmacological analgesics. Other groups instead of analgesics received a PL session. The 3 rd group received an analgesic injection and immediately afterwards got PL application. Control animals received a simulated light therapy session.

Each mouse was used only in one experiment and at the end it was put to sleep by a lethal dose of urethane (intraperitoneally). To reduce the effect of circadian rhythms on the nociceptive sensitivity of animals [14], all experiments were conducted at the same time of the light part of the day (from 10 to 13 hours).

\subsection{Creation of the Locus of Pain}

The locus of inflammatory somatic pain was induced by subcutaneous injection of $30 \mu \mathrm{L}$ of a $5 \%$ formalin solution (in $0.9 \% \mathrm{NaCl}$ solution) into the back surface of the left hind limb. At the injection site, there appeared reddening and swelling, which lasted for several hours. The pain intensity indicator was the duration of the painful reaction (licking of the affected limb) and non-painful (running, washing, sleeping, eating) behavioral responses for 10-min intervals and during 60 minutes of observation.

This test is a classical model of the tonic chemo-genic pain $[12,13]$. The formalin-induced pain response consists of two phases. The early phase (acute pain caused by irritation of painful skin receptors) begins immediately after the injection of formalin and lasts up to 10 minutes. The late phase (tonic pain, which is the consequence of the inflammatory process), begins after the 10th min and lasts more than an hour. Since in our experiments, immediately after the formalin solution injection, to do the 10-min light application, the mouse was placed in the chamber, partially limiting its motor activity, the early phase of the pain reaction was not recorded. Further, we will only talk about the latter-tonic pain.

With the help of a computer program, we calculated the duration of pain and non-painful behavioral responses for each consecutive $10 \mathrm{~min}$, and for the entire observation period (60 $\mathrm{min})$ as a whole.

\subsection{Applications of Polarized Light}

Immediately after the creation of the inflammatory pain locus, we performed 10-min applications by PL to the analgesic AP E-36, located in the upper-external part of the tibia. BIOPTRON-Compact device was the PL source with a polychromatic filter (produced by Bioptron AG, Zepter, Switzerland), radiating a linearly polarized (up to 95\%), incoherent, low-energy (40 $\mathrm{mW} / \mathrm{cm}^{2}$ ) light with a wavelength range of 480-3,400 $\mathrm{nm}$ in the visible and near infrared spectrum [15]. The distance from the light filter to the illuminated surface of the skin was $5 \mathrm{~cm}$. The light spot diameter of the device was $40 \mathrm{~mm}$, but for these experiments we used a diaphragm with a hole of $5 \mathrm{~mm}$. After the 10-min session, we recorded the beginning and the end of each cycle of the above pain and non-painful behavioral reactions during $60 \mathrm{~min}$ of observation. 


\subsection{Injections of Pharmacological Drugs}

In those groups where we studied the effects of pharmacological analgesics, each animal immediately after creation of the locus of pain, was injected with a solution of ibuprofen (Ibuprofen-solution, SIGMA-OLDRICH), analgin (analgin, Ukraine, Darnitza) or tramal (Tramadol®/Tramadol hydro-chloric, Poland, after the license of GrunenthalGmdH). Preparations were injected intraperitoneally, $0.2 \mathrm{~mL}$ in $0.9 \% \mathrm{NaCl}$ solution.

Ibuprofen was used in doses of 5, 10, 15, 20, 30 and $40 \mathrm{mg} / \mathrm{kg}$ (for comparison: the dose of the drug for a person is from $20 \mathrm{mg} / \mathrm{kg}$ to $40 \mathrm{mg} / \mathrm{kg}$ per day in several ways). Analgin was used in doses of 4.2 or $8.3 \mathrm{mg} / \mathrm{kg}$. Tramal was used in doses of 1.7 or $0.8 \mathrm{mg} / \mathrm{kg}$. These figures were obtained by recalculating one-time average and maximum analgesic doses of these drugs for an adult person, weighing $60 \mathrm{~kg}[16,17]$.

Then the animal was placed in a small chamber with a hole for the hind leg and held there for 10 minutes in the position with the elongated leg. This was done to accurately reproduce the experimental conditions applying PL. In the experiments with the combined use of PL and analgesic, during these $10 \mathrm{~min}$ the PL was applied to AP E-36 or to the locus of pain. After this we recorded the above behavioral responses.

\subsection{Statistical Analysis}

With the help of a special computer program, we calculated the duration of pain and non-painful behavioral reactions for every consecutive 10-min intervals of time and for the entire observation period (60 min). Experimental data are presented as mean \pm SEM. The reliability of the difference between the groups was determined by the student's test ( $t$-test). The difference was considered statistically significant at $p<0.05$.

\section{Results}

\subsection{Effects of Ibuprofen and Polarized Light on} Formalin-Induced Somatic pain

\subsubsection{Determination of the Dose of Ibuprofen,} Optimal for Pain Suppression

To select the optimal dose for pain suppression, we investigated the action of the following ibuprofen concentrations 5, 10, 15, 20, 30 and $40 \mathrm{mg} / \mathrm{kg}$ (Fig. 1).

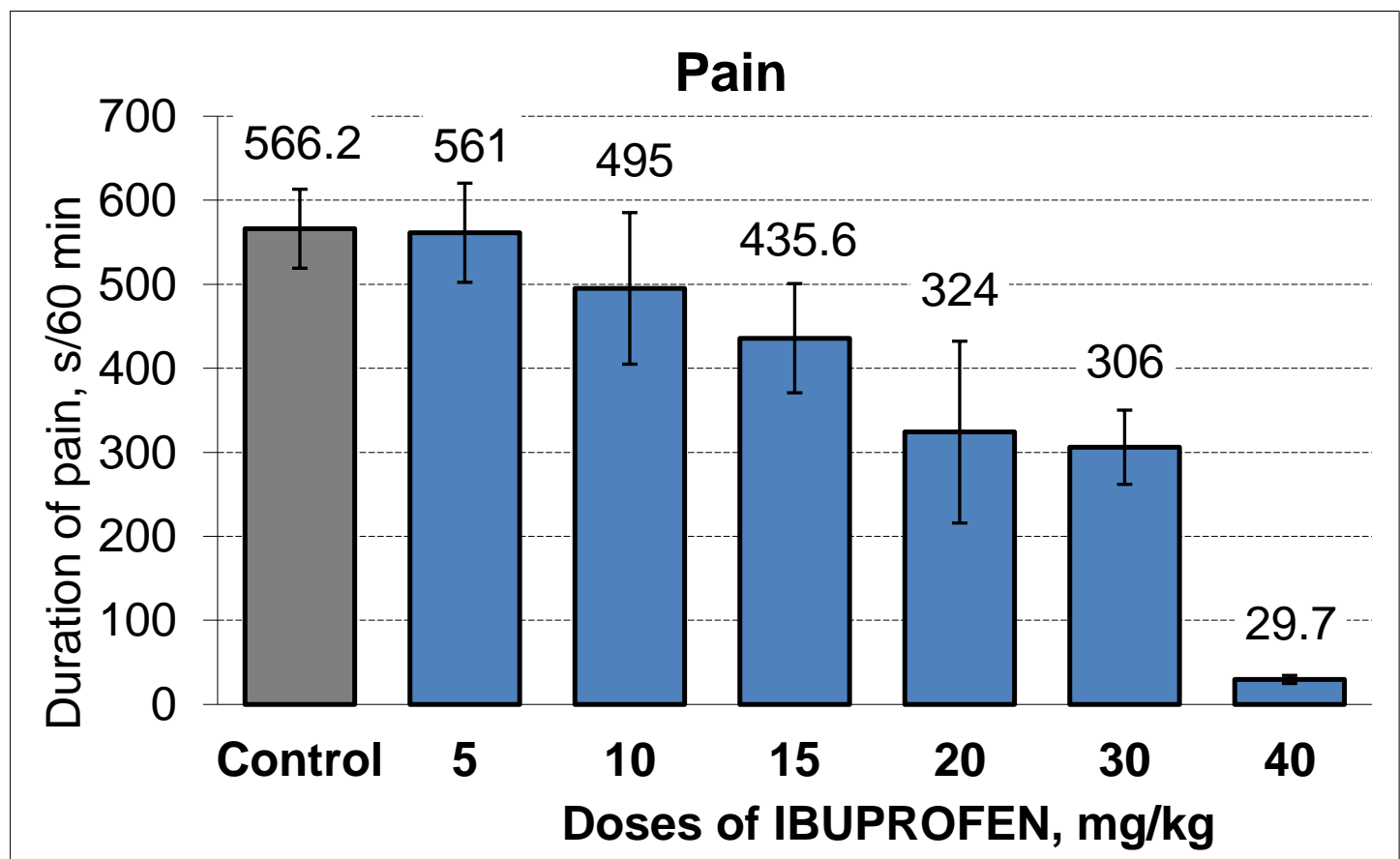

Fig. 1 Duration of the pain reaction in 60 minutes of observation, depending on the dose of ibuprofen. This and subsequent figures indicate mean \pm SEM. 
As you can see from Fig. 1, a minimal pain reaction occurred in the group where the animals received the ibuprofen dose of $40 \mathrm{mg} / \mathrm{kg}$. The duration of pain in this group was 29.7 seconds compared to 566.2 seconds in the control group. The pain attenuation compared to the control group was $94.8 \%$. The difference is statistically significant $(p<0.001)$. However, this concentration of ibuprofen cannot be considered optimal, since animals that received the ibuprofen dose of $40 \mathrm{mg} / \mathrm{kg}$ were in a hindered state, indicating an overdose of the drug (toxic dose). Most of the time the animals sat motionless with their eyes open. They did not eat, did not drink, practically did not run and did not wash.

Ibuprofen small doses (5 and $10 \mathrm{mg} / \mathrm{kg}$ ) did not make a significant pain reduction. These doses can be considered ineffective. The use of ibuprofen in doses of 15,20 and $30 \mathrm{mg} / \mathrm{kg}$ caused a statistically significant decrease in the duration of the pain reaction. The duration of pain was 76.9, 57.2 and $54 \mathrm{~s}$, respectively (vs. $566.2 \mathrm{~s}$ in the control). Analgesia was 23.1, 42.8 and $46 \%$ respectively.
Based on the experiments, the ibuprofen dose of 30 $\mathrm{mg} / \mathrm{kg}$ was found to be optimal, as it caused analgesic effect (46\% analgesia) without significant effect on non-painful behavioral responses. When the dose was raised up to $40 \mathrm{mg} / \mathrm{kg}$, there were clear signs of intoxication.

3.1.2 Investigation of the Effectiveness of the 50\% Dose of Ibuprofen for Pain Suppression (without Light Exposure)

The results of the evaluation of the dynamics and summary values of pain reactions on the $50 \%$ dose of ibuprofen $(15 \mathrm{mg} / \mathrm{kg})$ are shown in Fig. 2. One experimental group received the optimal dose (30 $\mathrm{mg} / \mathrm{kg}$ ) of ibuprofen injection and the second $-50 \%$ of the optimal dose $(15 \mathrm{mg} / \mathrm{kg})$.

It can be seen that the pain reaction in the group treated with a $50 \%$ ibuprofen dose $(15 \mathrm{mg} / \mathrm{kg})$ is intermediate between the control and the optimal analgesic dose $(30 \mathrm{mg} / \mathrm{kg})$. Differences are most noticeable in the first 30-40 minutes (Fig. 2A). Comparison of the mean values (over $60 \mathrm{~min}$ of observation) of pain duration in the three groups (Fig. 2B)

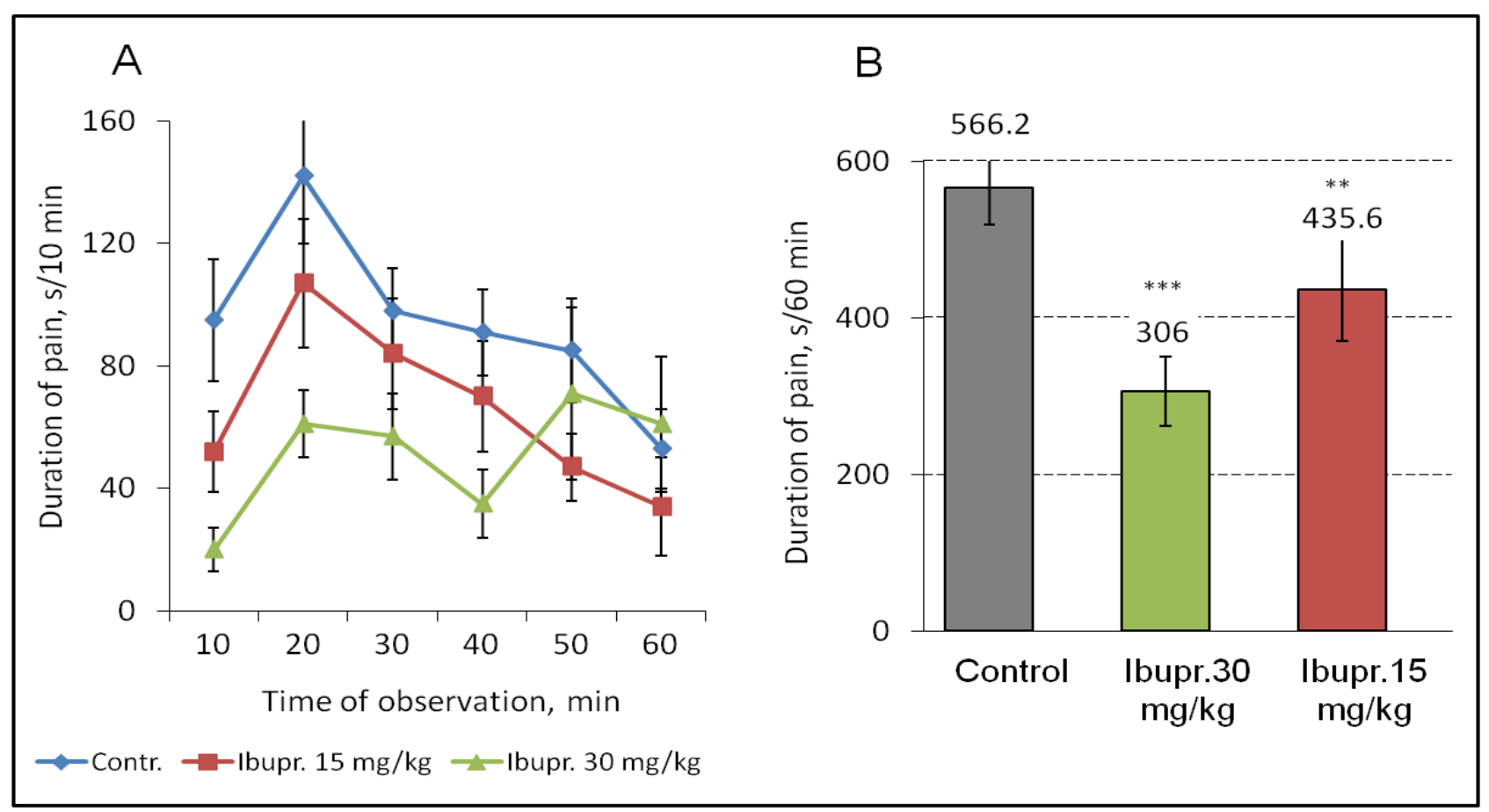

Fig. 2 Dynamics (A) and the total duration (B) of the pain response in animals receiving the ibuprofen optimal dose (30 $\mathrm{mg} / \mathrm{kg})$, and a $50 \%$ dose $(15 \mathrm{mg} / \mathrm{kg})$ compared to the control. 
showed that both experimental groups differ from the control group with a high degree of reliability. The difference between the two experimental groups is also reliable.

The above experimental data suggest that ibuprofen shows an adequate effect in relation to the model of tonic pain. This assures in the possibility of further studies of the effect of combined use of PL and ibuprofen.

\subsubsection{Pain Suppression by Application of} Low-Intensity Polarized Light to AP E-36

We considered the results of a series of experiments on animals with an experimentally-induced locus of somatic pain (formalin test), who received PL application on AP E-36. Throughout the whole period in a group where we applied PL, the pain response was weaker compared to the control group (Fig. 3). At the same time, monitoring the dynamics of sleep showed that animals, who received a PL session, slept longer than the control animals.

The duration of reactions in general for $60 \mathrm{~min}$ of observation in the two groups was significantly different (Table 1). In the group where animals immediately after the creation of the locus of somatic pain received a PL session to AP, the pain was $413.7 \mathrm{~s}$

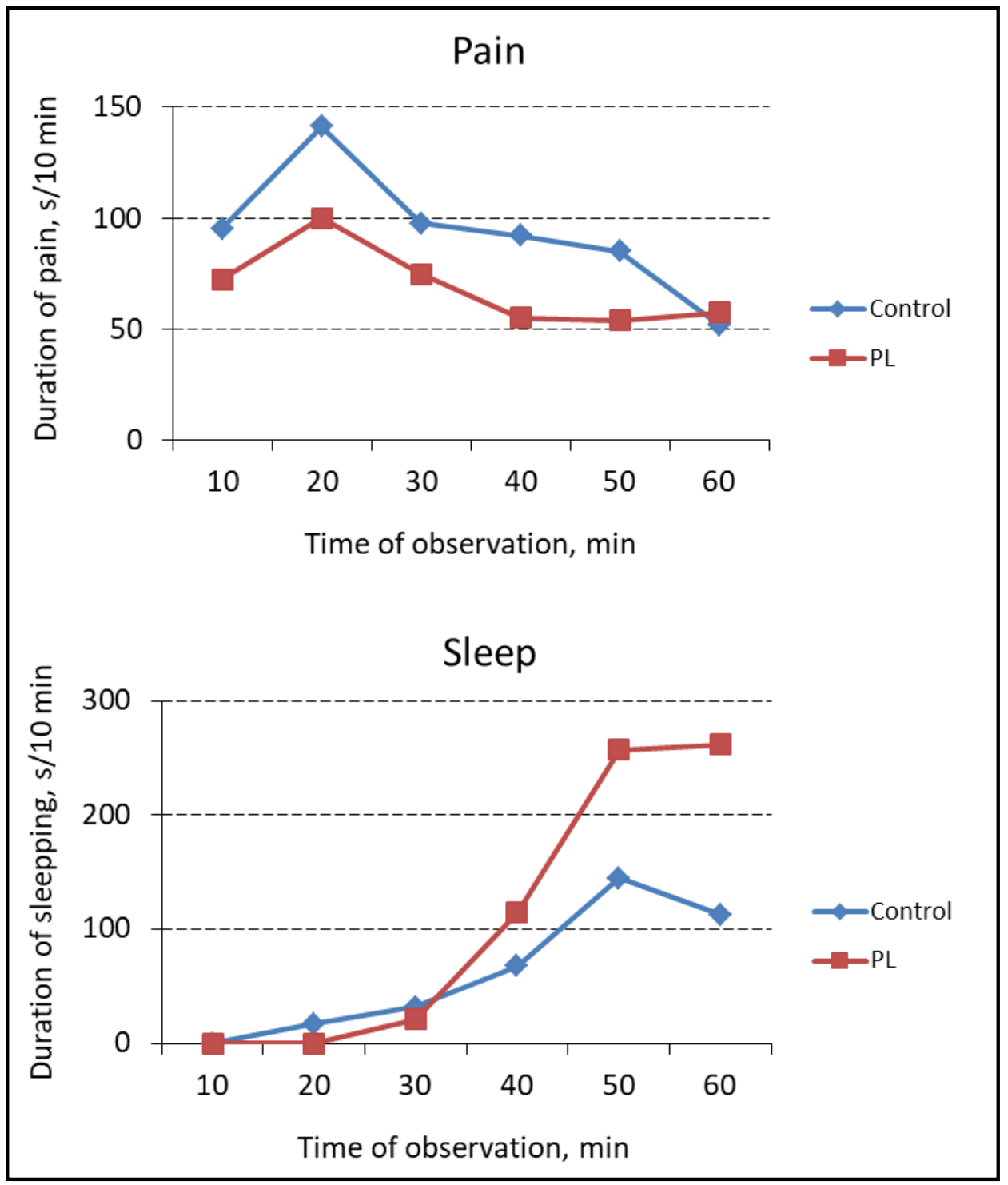

Fig. 3 Dynamics of pain reaction and sleep after a 10-minute application to acupuncture point E-36 of low-intensity polarized light of the BIOPTRON device with a polychromatic filter in comparison with the control. 
Table 1 Mean values of the duration of pain and non-painful behavioral responses within 60 min of observation in the control group (without light applications) and in the experimental group, where 10-min action of polychromatic polarized BIOPTRON light on the acupuncture point E-36 was applied.

\begin{tabular}{lll}
\hline Reactions & Control (placebo) & $\begin{array}{l}\text { Polychromatic polarized light } \\
\text { (action on AP E-36) }\end{array}$ \\
\hline Pain & $566.2 \pm 47.1 \mathrm{~s}$ & $413.7 \pm 42.8 \mathrm{~s} * * *$ \\
Sleeping & $100 \%$ & $73.1 \%$ \\
Washing & $386.3 \pm 79.3 \mathrm{~s}$ & $668.8 \pm 118.6 \mathrm{~s} * *$ \\
& $100 \%$ & $173.1 \%$ \\
Running & $137.9 \pm 32.5 \mathrm{~s}$ & $324.2 \pm 60 \mathrm{~s} * * *$ \\
Eating & $100 \%$ & $235.1 \%$ \\
& $65.5 \pm 13 \mathrm{~s}$ & $45.5 \pm 7.3 \mathrm{~s} *$ \\
\hline
\end{tabular}

Reliability of the difference in comparison with the control: $* * * p<0.05 ; * * p<0.1 ; * p<0.5$.

compared to $566.2 \mathrm{~s}$ in the control. The reliability of the difference is high $(p<0.05)$. The total duration of the pain reaction was $73.1 \%$ of the control value, and analgesia was on average $26.9 \%$. Statistically significant changes were also experienced by all non-painful behavioral reactions. They (with the exception of running) became longer, which also indicated to the pain easing under the influence of low-intensity polychromatic PL.

This experiment showed that PL has an analgesic effect comparable to that of an analgesic ibuprofen in a $50 \%$ dose $(15 \mathrm{mg} / \mathrm{kg})$.

3.1.4 The Effects of Combined Use of Polarized Light and Ibuprofen

After combined use of the PL and a 50\% dose of ibuprofen throughout the entire observation hour, the pain response was less intense than in the groups where the animals received only PL or ibuprofen (Fig. 4).

Table 2 clearly shows that both pain and non-painful reactions in the group receiving half of the dose of ibuprofen in combination with PL application statistically significantly differ from similar reactions registered in the group where only one analgesic was used (taken as $100 \%$ ). The pain was $68.7 \%$, i.e. 1.5 times weaker than in animals that received only the analgesic. At the same time, the duration of sleep increased 2.9 times, which also indicated pain reduction. Consequently, the combined use of ibuprofen and PL suppresses pain more effectively than the analgesic alone. The 10-min PL application to the AP allows, with a low dose of an analgesic (50\% of a dose) to obtain an effect comparable to the action of a twice larger dose (Fig. 5).

Comparison of the intensity of the pain response in different experimental groups (Fig. 5) showed a significant pain relief under the action of both ibuprofen and the BIOPTRON light (with a polychromatic filter). The effect of PL was approximately the same as that as $50 \%$ of ibuprofen dose. But in the case of combined use of 50\% ibuprofen dose and PL, the analgesic effect was almost the same as that produces by ibuprofen in the optimal dose $(30 \mathrm{mg} / \mathrm{kg})$. Analgesia of the $50 \%$ dose of ibuprofen was $23.1 \%$, and in case of combination with PL- $47.1 \%$ (2 times more). This means that the PL allowed to halve the dose of ibuprofen, i.e. the effect of a 50\% ibuprofen dose can be potentiated by PL action on the analgesic AP.

\subsection{Effects of Analgin and Polarized Light of the BIOPTRON Device on the Somatic Pain}

3.2.1 Comparison of the Effects of the Use of Polarized Light and Analgin

The scheme of the study was similar to that described above. We conducted a comparative evaluation of the effectiveness of analgesia by injection of analgin and the action of PL (Fig. 6). Doses of analgin were $8.3 \mathrm{mg} / \mathrm{kg}$ (optimal) and $4.2 \mathrm{mg} / \mathrm{kg}$ $(50 \%)$. 


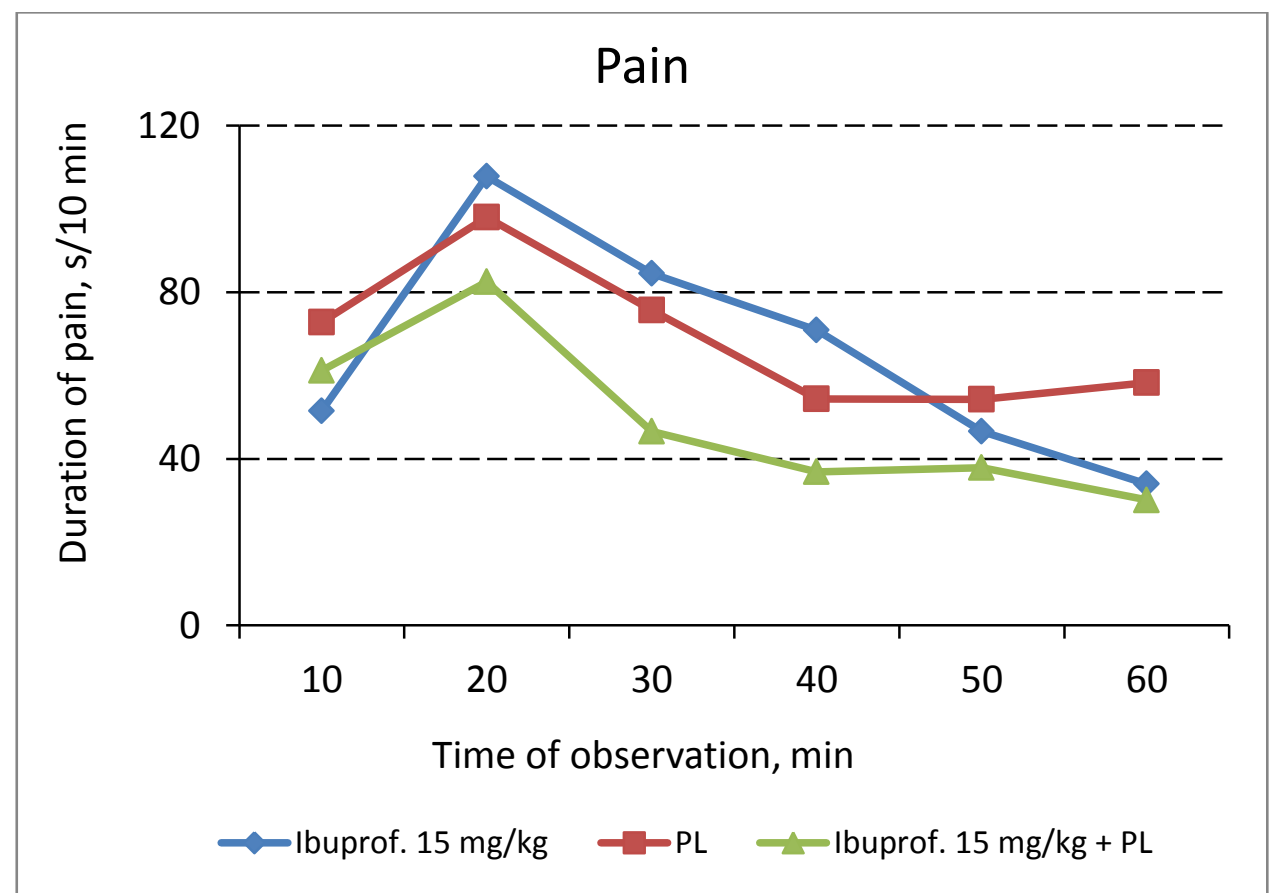

Fig. 4 Dynamics of the pain response after the ibuprofen injection (a dose of $15 \mathrm{mg} / \mathrm{kg}$ ), a 10-min application to the acupuncture point E-36 by BIOPTRON polarized light (PL) with a polychromatic filter and joint use of ibuprofen and PL.

Table 2 Comparison of the duration of painful and non-painful behavioral responses in two experimental groups, one of which immediately after the locus of pain creation received the ibuprofen injection $(50 \%$ of a dose), and the second similar injection and a 10-min application of BIOPTRON device PL (with a polychromatic filter) on acupuncture point. The total duration of the reaction for $60 \mathrm{~min}$ of observation.

\begin{tabular}{lll}
\hline Reactions & Ibuprofen $(15 \mathrm{mg} / \mathrm{kg})$ & $\begin{array}{l}\text { Ibuprofen }(15 \mathrm{mg} / \mathrm{kg}) \\
+ \text { PL on AP E-36 }\end{array}$ \\
\hline Pain & $435.6 \pm 65 \mathrm{~s}$ & $299.3 \pm 38.6 \mathrm{~s} * * *$ \\
Sleeping & $100 \%$ & $68.7 \%$ \\
Washing & $355 \pm 90 \mathrm{~s}$ & $1,023.6 \pm 175.8 \mathrm{~s} * * *$ \\
Running & $100 \%$ & $288.3 \%$ \\
Eating & $183.9 \pm 25 \mathrm{~s}$ & $129.5 \pm 27.8 \mathrm{~s}^{*}$ \\
\hline
\end{tabular}

Reliability of the difference between the groups: $* * * p<0.05 ; * * p<0.01 ; * * p<0.5$.

In all three experimental groups, we observed a statistically significant reduction in the duration of the pain reaction. The group of animals that received the PL session on AP E-36 occupied an intermediate position between the two groups in which analgin was used. The total time of painful behavioral response in animals receiving analgin in a dose of $4.2 \mathrm{mg} / \mathrm{kg}$ was $673.9 \mathrm{~s}$, and at a dose of $8.3 \mathrm{mg} / \mathrm{kg}-243.6 \mathrm{~s}$. This amounted to 71.5 and $25.9 \%$ of the control. The difference between the two experimental groups is statistically significant $(p<0.001)$. After a 10-min light application, the duration of the pain reaction was 471.3 s compared with $942.1 \mathrm{~s}$ in the control group, that is, halved. The PL effect was significantly higher than that of analgin in a dose of $4.2 \mathrm{mg} / \mathrm{kg}$, but lower than that of analgin in a dose of $8.3 \mathrm{mg} / \mathrm{kg}$.

From the non-painful behavioral reactions, it is most interesting to note the features of sleeping and eating behavior in different experimental groups. After the analgin injection in a dose of $8.3 \mathrm{mg} / \mathrm{kg}$, none of 10 mice 


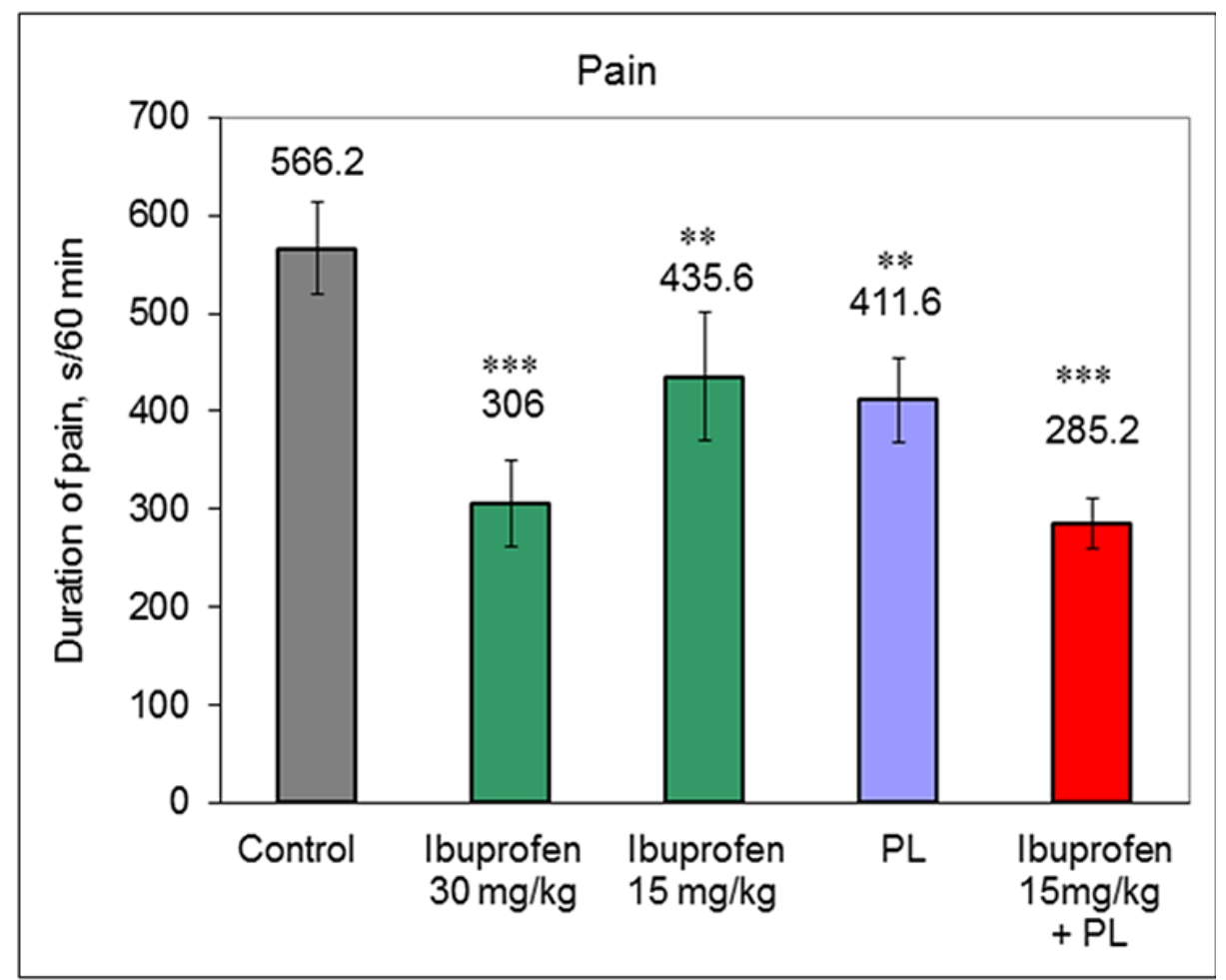

Fig. 5 The duration of the pain reaction during 60 minutes of observation in the control group (placebo) and in the four experimental groups that received the optimal $(30 \mathrm{mg} / \mathrm{kg})$ and $50 \%(15 \mathrm{mg} / \mathrm{kg})$ dose of ibuprofen, $10 \mathrm{~min}$ application to AP E-36 by polarized light or combined use of ibuprofen $(50 \%$ dose $)$ and polarized light.

Reliability of the difference with the control: $* * * p<0.001 ; * * p<0.1$.
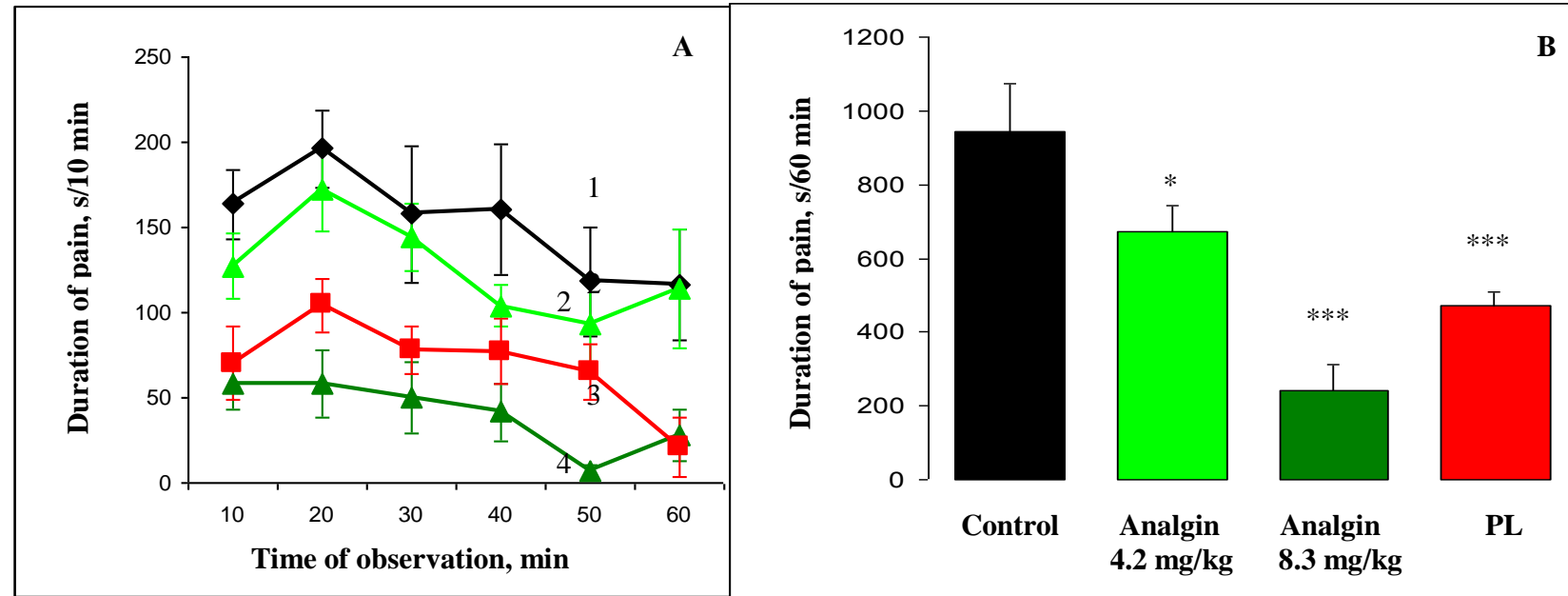

Fig. 6 Comparison of the effects of analgin and polarized light on the duration of pain response in mice with a locus of tonic pain: (A) Dynamics of pain process development. (B) Comparison of the total (60 min of observation) duration of painful behavioral response in mice in the control and three experimental groups. 1—Control group; 2-Analgin 4.2 mg/kg; 3 -PL; 4-Analgin $8.3 \mathrm{mg} / \mathrm{kg}$.

Reliability of the difference with the control: $* * * p<0.001 ; * * p<0.01 ; * p<0.05$.

in $60 \mathrm{~min}$ of observation did not touch the feed. However, in the group where the PL was applied to AP E-36, feeding did 6 out of 10 mice, sleeping duration of these animals was almost twice as long as of the control animals (1,261.8 and $557.3 \mathrm{~s}$, respectively).

In animals that received high doses of analgin, 
inhibition arose; they spent a considerable part of the time in a stationary state with their eyes open (frozen posture). This was never observed in the animals of the group receiving $\mathrm{PL}$, whose behavior was closer to the natural.

3.2.2 The Effects of Combined Use of Polarized Light and Analgin

The PL analgesic effect in combination with analgin (50\% dose) is shown in Fig. 7. The first experimental group received injections of a solution of analgin in a dose of $4.2 \mathrm{mg} / \mathrm{kg}$, the second group - in addition to analgin solution injecting $(4.2 \mathrm{mg} / \mathrm{kg})$ underwent a 10-min action of PL on AP E-36. It can be seen that analgin in combination with PL suppresses pain more than without stimulation of AP.

The total duration of the pain response in 60 minutes of observation in animals treated with analgin in a dose of $4.2 \mathrm{mg} / \mathrm{kg}$ was $673.9 \mathrm{~s}(71.5 \%$ of the control). If PL additionally acted on AP E-36, the duration of the pain reaction was significantly $(p<0.01)$ reduced, down to $498.2 \mathrm{~s}$ ( $52.9 \%$ of the control). Analysis of non-painful behavioral responses showed that animals that beside analgin received PL in addition, were more mobile (running time double increased), and they also had more pronounced grooming.

\subsection{The Effect of Tramal and BIOPTRON Polarized Light on the Somatic Pain}

3.3.1 Comparison of the Analgesic Effect of Tramal and BIOPTRON Polarized Light

We evaluated the effects of tramal (doses of 0.8 and $1.7 \mathrm{mg} / \mathrm{kg}$ ) and PL application. It was found that the pain response was weaker in the animals treated with tramal than in the control (Fig. 8). At the same time, a dose of $1.7 \mathrm{mg} / \mathrm{kg}$ had a more pronounced analgesic effect compared to a dose of $0.8 \mathrm{mg} / \mathrm{kg}$. If we summarize all the episodes of licking of the locus of tonic pain per hour of observation, the total duration of the pain reaction at a dose of $1.7 \mathrm{mg} / \mathrm{kg}$ was $412.9 \mathrm{~s}$, and at a dose of $0.8 \mathrm{mg} / \mathrm{kg}-620.2 \mathrm{~s}, 942.1 \mathrm{~s})$. The difference in control for both groups is statistically significant $(p<0.01 ; p<0.05)$.

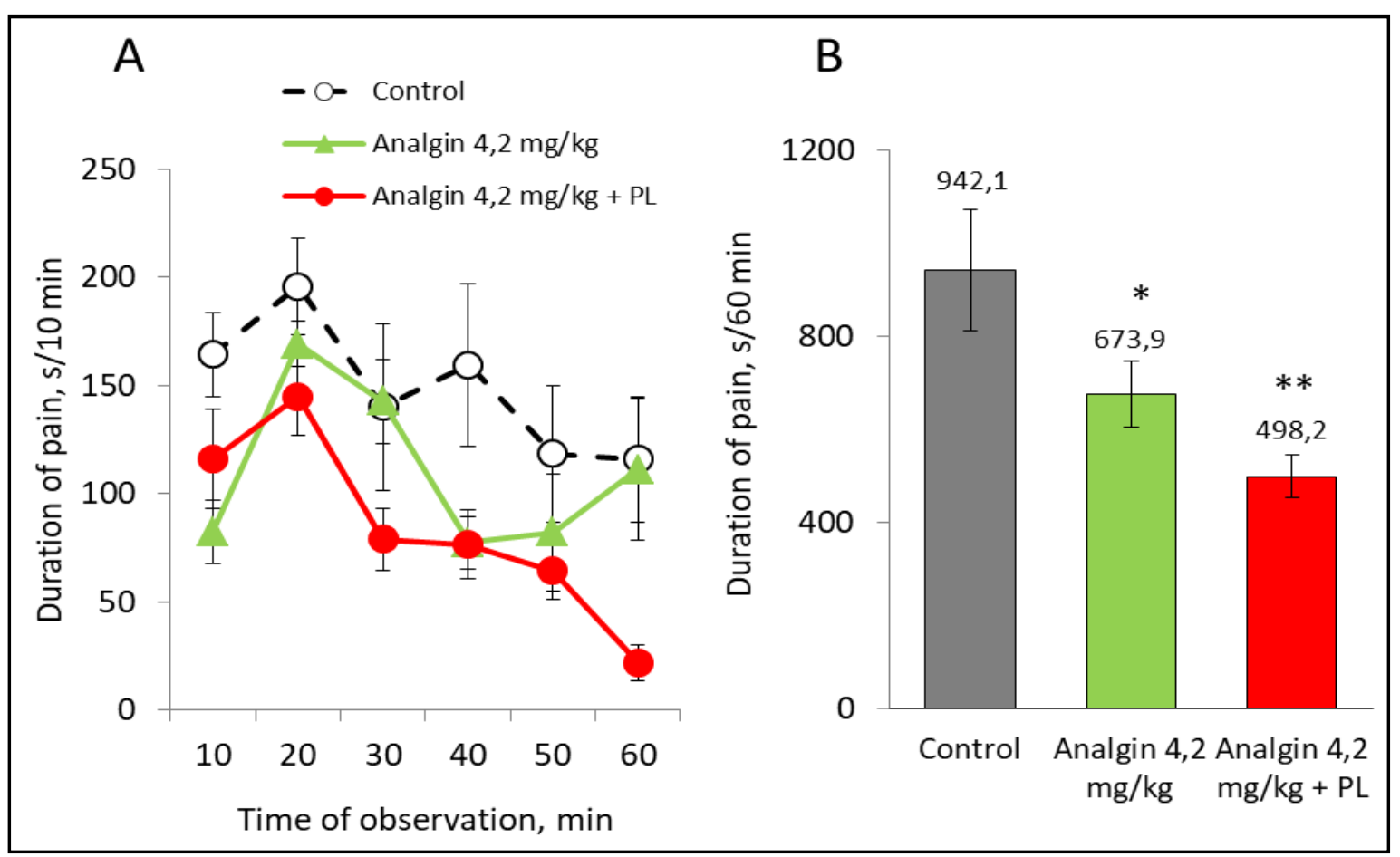

Fig. 7 Dynamics (A) and total duration in 60 minutes of observation (B) of painful behavioral response in mice of the control group, analgin-treated mice, and mice that, in addition to analgin, underwent a 10-min action of PL on AP E-36. Reliability of the difference with the control: ** $p<0.01 ; * p<0.05$. 


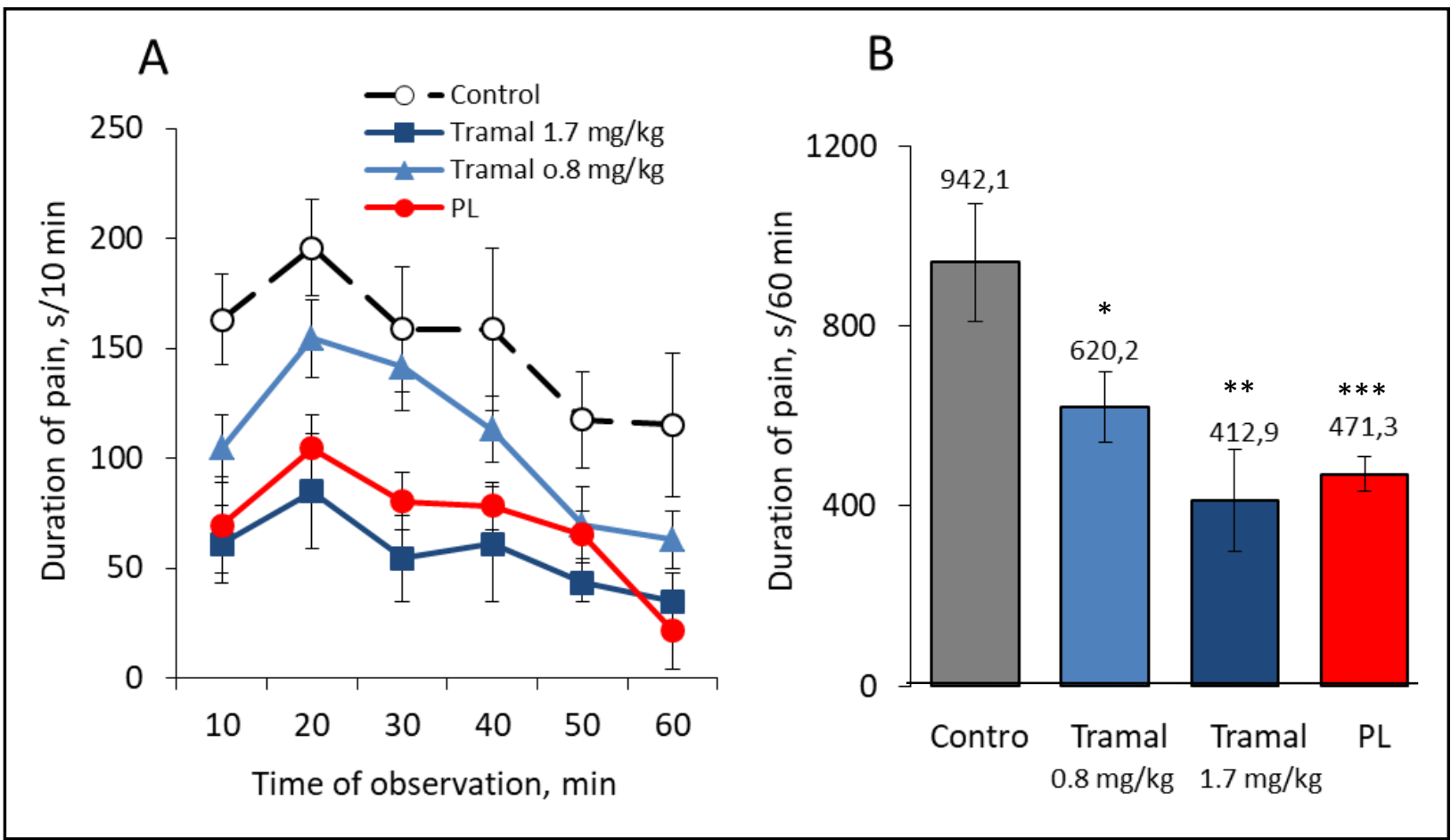

Fig. 8 Comparison of the influence of tramal (in doses of 1.7 and $0.8 \mathrm{mg} / \mathrm{kg}$ ) and polarized light on the duration of pain reaction in mice with a locus of tonic pain. (A) Dynamics of the pain process development in mice of the control and three experimental groups. (B) Total (for 60 min of observation) duration of painful behavioral reaction in different groups. Reliability of the difference with the control: *** $p<0.001$; ** $p<0.01 ; * p<0.05$.

As to the effectiveness of pain suppression, PL occupied an intermediate position between the two groups where tramal was used. The total duration of the painful behavioral response in the animals treated with tramal was $43.8 \%$ (at a dose of $1.7 \mathrm{mg} / \mathrm{kg}$ ) and $65.8 \%$ (at a dose of $0.8 \mathrm{mg} / \mathrm{kg}$ ), and in animals that received only a PL session on AP E-36, $-50 \%$ of the value in the placebo group.

Of the non-painful behavioral responses, the greatest differences between the groups where the tramal and the PL were used were in sleeping and eating behavior. The sleep duration compared with the control, in the group receiving tramal, increased insignificantly, while under the PL influence, it increased approximately twice. In groups where tramal was used in a dose of 1.7 $\mathrm{mg} / \mathrm{kg}$, only one mouse out of 10 for a short time ate feed (in control, only one mouse out of 10 ate feed). However, in the group where the analgesic effect was caused by the action of PL on TA E-36, six of ten mice ate feed.
Animals, who received large doses of tramal, were in the inhibited state for a considerable part of the time (immobility with open eyes). This was never observed after PL applications to analgesic AP E-36.

\subsubsection{The Effects of the Combined Use of Polarized} Light and Tramal

It was found that the PL in combination with tramal caused more powerful suppression of pain than the use of only one tramal (Fig. 9). We compared the effects of tramal in a dose of $1.8 \mathrm{mg} / \mathrm{kg}$ and the combined use of tramal in the same dose + 10-minute exposure to PL of AP E-36.

The total duration of the painful behavioral reaction per hour of observation at a dose of tramal $0.8 \mathrm{mg} / \mathrm{kg}$ was $65.8 \%$ of the control value (without the use of PL). At the combined use of PL with tramal in the same dose $(0.8 \mathrm{mg} / \mathrm{kg})$, the pain was reduced down to $49.3 \%$ in comparison with the control. The difference between the two experimental groups is statistically significant. Animals that received an additional PL session were 


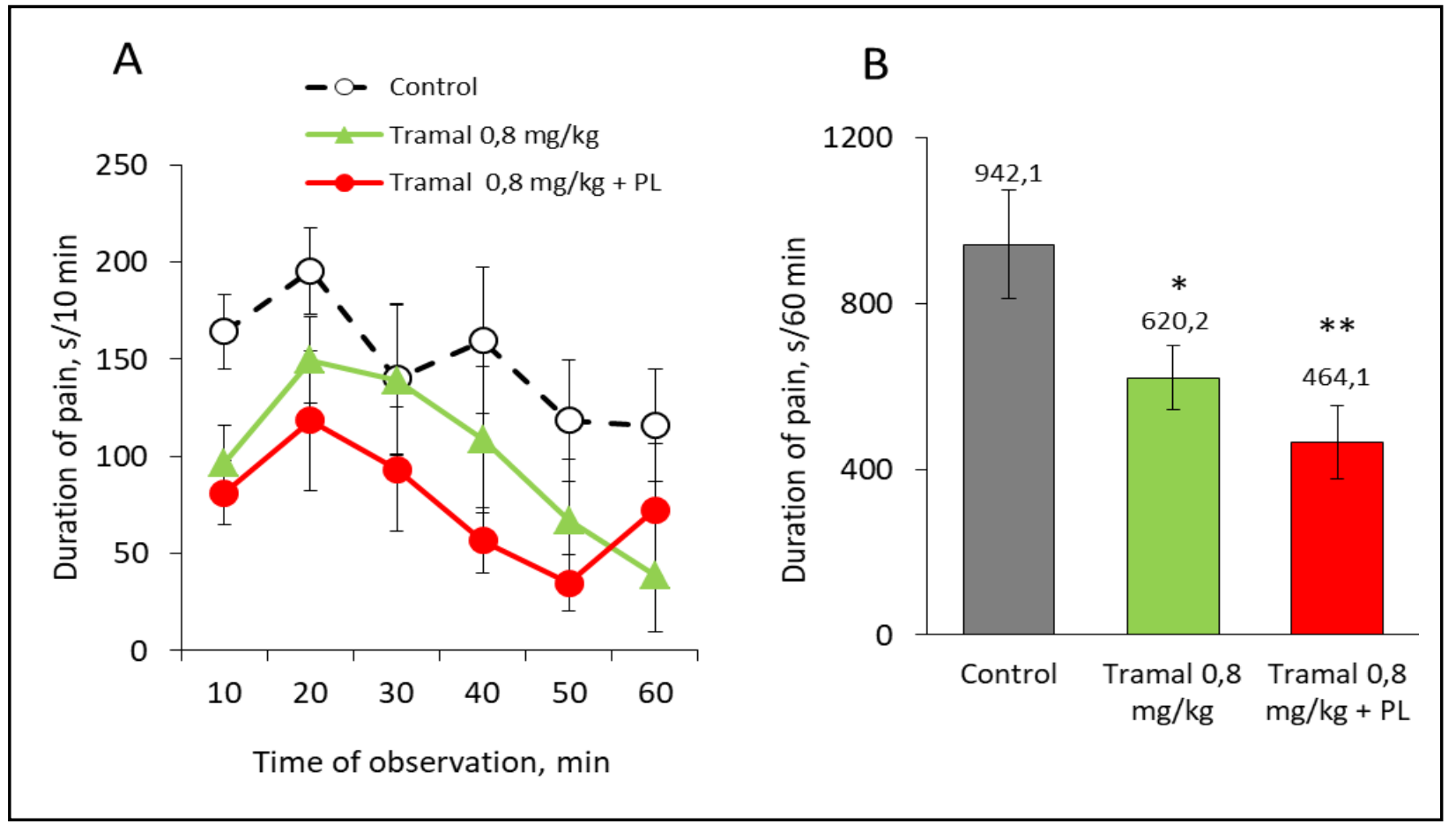

Fig. 9 Dynamics (A) and the total duration in 60 minutes of observation (B) of the painful behavioral response in the animals of the control group, the group receiving the tramal, and the group that additionally received a 10-minute PL application to AP E-36.

Reliability of the difference with the control: $* * p<0.01 ; * p<0.05$.

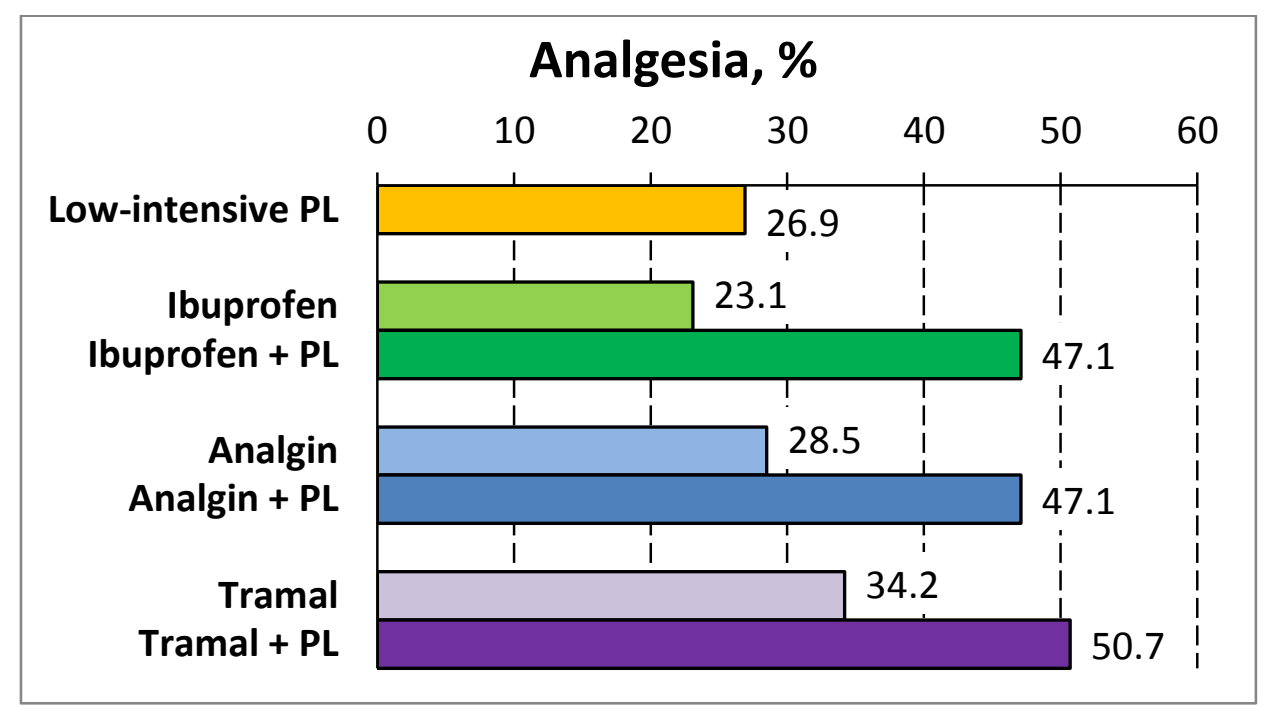

Fig. 10 The effect of the low-intensity polarized light on the analgesic effect of pharmacological analgesics at $50 \%$ of the optimal doses: ibuprofen (15 mg/kg), analgin $(4.2 \mathrm{mg} / \mathrm{kg})$ and tramal $(0.8 \mathrm{mg} / \mathrm{kg})$.

more mobile. However, they had no interest to food, as other animals. The duration of sleep was not reliable.

So, the results show that the combined use of PL and analgesics (ibuprofen, analgin, tramal) gives a significant analgesic effect at smaller doses. So, if one ibuprofen (at a dose of $15 \mathrm{mg} / \mathrm{kg}$ ) weakened the pain by $23.1 \%$, and one analgin (a dose of $4.2 \mathrm{mg} / \mathrm{kg}$ ) or a single tramal $(0.8 \mathrm{mg} / \mathrm{kg}$ dose $)$ weakened the pain by $28.5 \%$ and by $34.2 \%$, the combination of these analgesics (in the same doses) with PL increased 
analgesia up to $47.1 \%, 47.1 \%$ and $50.7 \%$, respectively (Fig. 10).

\section{Discussion}

The main achievements of this work are: (1) For the first time, it was shown that the analgesic effect of low-intensity PL is comparable with the effect of moderate doses of pharmacological analgesics; (2) For the first time, it has been experimentally proven that the combined use of an analgesic and a PL suppresses pain more effectively than one analgesic in the same dose.

Widely used drugs for pain suppression-ibuprofen, analgin and tramal in doses equivalent to a single dose for humans, on the model of experimentally induced tonic pain (formalin test) weakened the pain by 46.0, 74.9 and $56.2 \%$, respectively. Half doses of these drugs caused analgesia $23.1,28.5$ and $34.2 \%$. A statistically significant reduction in pain was also observed in groups where, instead of analgesics, a 10-min PL application was used to analgesic AP E-36 (27.0\%) or to the locus of pain (by 35.8\%).

The mechanisms of the analgesic effect of the pharmacological drugs used by us have been studied in some detail today. Analgin has been shown to cause an analgesic effect due to direct activation of endogenous opioid systems [20], potentiation of the action of endogenous opioids [21], as well as blocking the action of analgesics on the endings of nociceptive terminals $[22,23]$. Tramal activates opioid mu-receptors, and also inhibits the re-uptake of norepinephrine, enhances the effect of serotonin and facilitates the action of dopamine in brain neurons [24, 25].

Regarding the PL anti-nociceptive mechanisms, they are less well studied. Earlier we have shown that pain can be weakened by the influence on AP not only by PL of the halogen nature [7], but also by polarized LED-light [26]. As a result of the effects of PL on AP, there are triggered the descending analgesic systems of the brain, which leads to suppression of transmission of pain impulses at the neuronal level. Such a mechanism has now been proven to exist in case of impact on AP by electric current or by low-intensity electromagnetic radiation of the microwave range. Microwaves with a flow rate of $10^{-6}$ to $10^{-12} \mathrm{~W} / \mathrm{cm}^{2}$ when influencing on AP cause analgesia in mice with tonic pain through opioid and serotonergic system of the brain stem [27, 28]. Our previous studies indicate that opiate receptors play an important role in the analgesic effect of PL on AP [29]. This conclusion is consistent with the data obtained in respect of the mechanisms of electro-acupuncture analgesia, which has been studied much better [30-32]. It is known that electrostimulation of the same AP that was used in our experiments (E-36) suppresses the answers of convergent neurons of the dorsal horn caused by nociceptive stimulation of the hind-limb [33]. Our experiments [29] demonstrate the involvement of the opioid system in providing an analgesic effect by a low-intensity PL when it is applied to AP. However, it should be noted that even a high dose of naloxone does not eliminate the analgesic effect of PL completely. This indicates that other analgesic systems of the brain, possibly serotonergic, dopaminergic, noradrenergic, etc., also participate in the PL implementation in the pain effect.

In this study, it was shown for the first time that the effect of small doses of analgesics can be significantly (approximately 1.5-2 times) potentiated by the action of PL on the analgesic AP [34]. Such a mutual enhancement was also observed when acupuncture was combined with pharmacological preparations that inhibit the decay or re-uptake of opioid peptides and amines belonging to the anti-pain systems of the brain [18]. However, with the use of pharmacological compounds that block the synthesis of monoamines or opioid peptides, the analgesic effect of acupuncture weakened [19].

The mechanism of amplification by the PL of the effects of analgesics of the central action appears to be a complex and multistage process. It is known that the analgesic effect of classical acupuncture (with the introduction of a needle into AP) is carried out: (a) through activation of the descending analgesic systems; (b) through inhibition of neurons transmitting 
nociceptive information from the peripheral structures of the brain to its central structures; (c) due to increased synthesis of endogenous opioids by neurons of the brain-stem and hypothalamus. Thus, it is obvious that the interaction between the chemical effects of analgesics and the electromagnetic processes that arise in response to PL, occurs in the integrative structures of the brain stem, which comprises the analgesic systems.

Low-intensity electromagnetic waves cause complex physicochemical changes in the body, which activate a number of molecular processes. They can extend the stages of protein synthesis, change the conformational properties of their binding sites, cause twisting and vibrations, as well as rotation and reorientation of dipole molecules [35-37], and change the movement of ionized $\mathrm{Ca}^{2+}$ [38]. The energy of external EMW is converted into energy of chemical or mechanical processes when interacting with enzymes that have the corresponding electromagnetic characteristics [39]. Low-intensity EMW induce redistribution of membrane integral proteins, reorganization of microfilament structures, modulation of cell membrane channels [40], change in cytoskeleton orientation [41], activation of gene transcription [42], facilitating signal transfer between cells [43]. They alter the activity of enzymes, hormones, growth factors, cytokines, cell proliferation, DNA synthesis [44]. High-intensity electric currents, magnetic fields and EMW, causing tissue heating, negatively affect the subtle life processes. They modify and disrupt the functions of cells and body systems, and interact unpredictably with biological molecules and drugs [45-47]. Clinically, their effect is manifested in headaches, fatigue, disorders of sleep and vision, blood functions, digestive, excretory, endocrine and immune systems.

It should be emphasized that the potentiation of analgesia was obtained by us due to single combination of analgesics and PL. It is not yet known how analgesia will develop if the combination is repeated. It is known that with repeated and long-term administration of analgesics, especially large doses, along with pain suppression, undesirable side effects may occur, which also have in analgesics experienced by us: hematopoietic depression, allergy, motor and autonomic disorders, drug dependence, etc. To believe that the combination of pharmacotherapy and BIOPTRON PL will make it possible to use lower doses of analgesics in the clinic and, consequently, to reduce the risk of unwanted development of side effects.

\section{Conclusions}

It has been experimentally revealed that the analgesic effect of PL is comparable to the pain relief caused by the use of moderate doses of pharmacological analgesics (ibuprofen, analgin, tramal). The use of the formalin test model allowed doing quantitative determination of pain intensity in animals. The combined use of analgesic and PL on the acupuncture pain relief point E-36 suppresses pain more effectively than an isolated analgesic in the same dose. These data also prove the possibility of obtaining a biological effect in the case of non-contact application of PL to the AP. The clinical significance of these data is to prove the possibility of reducing the dose of analgesic drugs by applying polychromatic polarized light to specific biologically active zones, which reduces the risk of developing unwanted post-pharmacological side-effects.

\section{Acknowledgments}

This work became possible due to support of Philip Zepter, President of the Zepter International, and Vibor Mulič, Vice President of the Zepter International. The authors are also grateful to the contribution of Prof. Yu. P. Limansky (Bogomolets Institute of Physiology, NAS of Ukraine), who is no longer with us.

\section{References}

[1] Albu, R., Dragomir, P., and Voiosu, R. 1998. "Gastro-Intestinal Lesions Induced by Non-steroidal Anti-inflammatory Drug.” Rom. J. Intern. Med. 36 (34): 
145-59.

[2] Hersh, E., Moore, P., and Ross, G. 2000. "Over-the-Counter Analgesics and antipyretics: A Critical Assessment." Clin. Ther. 22 (5): 500-48.

[3] Gulyar, S., Limansky, Y., and Tamarova, Z. 1999. "Analgesic Effects of Bioptron PILER Light". J. of Practical Doctor (4): 21-3. (in Russian)

[4] Limansky, Y., Tamarova, Z., Bidrov, E., and Kolbun, N. 1999. "Suppression of Nociceptive Responses in Mice by Low-Intensity Microwave Exposure on Acupuncture Points." Neurophysiology 31 (4): 290-4. (in Russian)

[5] Limansky, Y., Tamarova, Z., Gulyar, S., and Bidrov, E. 2000. "Study of Analgesic Effect of Polarized Light on Acupuncture Points." Fiziol. J. 46 (6): 105-11. (in Ukrainian)

[6] Limansky, Y., Tamarova, Z., and Gulyar, S. 2003. "Suppression of Visceral Pain by Action of the Low Intensity Polarized Light on Antinociceptive Points of Acupuncture." Fiziol. J. 49 (5): 43-51. (in Ukrainian)

[7] Limansky, Y., Tamarova, Z., and Gulyar, S. 2006. "Suppression of Pain by Exposure of Acupuncture Points to Polarized Light." Pain Res. Manag. 11 (1): 49-57.

[8] Gulyar, S., Limansky, Y., and Tamarova, Z. 2006. "Suppression of Pain by Influence of Bioptron-Polarized Light on Acupoints." European J. Pain. 10: S212.

[9] Limansky, Y., Tamarova, Z., and Gulyar, S. 2008. "Suppression of Visceral Pain by Exposure of Acupuncture Points to Low-Intensive Polarized Light." Abstracts of the 12th World Congress on Pain. August 17-22. Glasgow, Scotland, UK.-Pres. PT 338.

[10] Tamarova, Z., Limansky, Y., and Gulyar, S. 2009. "Antinociceptive Effects of Color Polarized Light in Animal with Formalin Test.” Fiziol. J. 55 (3): 81-93. (in Ukrainian)

[11] Limansky, Y., Gulyar, S., and Tamarova, Z. 2009. "BIOPTRON-Analgesia: 12. Role of Color in Tonic Pain Suppression." In Anthology of Light Therapy. Medical BIOPTRON Technologies. Kyiv: Bogomoletz Institute of Physiology at the National Academy of Sciences of Ukraine, 722-31. (in Russian)

[12] Dubuisson, D., and Dennis, S. 1977. "The Formalin Test: A Quantitative Study of the Analgesic Effects of Morphine, Nepedioine and Brain Stem Stimulation in Rats and Cats." Pain 4: 161-74.

[13] Hunskaar, S., and Hole, K. 1987. "The Formalin Test in Mice: Dissociation between Inflammatory and Non-inflammatory." Pain 30: 103-4.

[14] Kavaliers, M., and Hirst, M., 1983. "Daily Rhythms of Analgesia in Mace: Effects of Age and Photoperiod." Brain Res. 279: 387-93.

[15] Gulyar, S.1999. "Dual Technology of Health Preservation in Environmentally Unfavorable Conditions: Synergism of PYLER Light and Antioxidants." Mater. Yubil. Scientific-Practical. Conf. Dedicated to 5-th Anniversary of Activity Zepter - International in Ukraine. Kiev: Zepter, 6-21.

[16] Mashkovskiy, M. 1985. "Medicinal Products: In 2 Volumes." Medicine. Moscow, 624.

[17] Farmindex-97. 1997. Reference book edited by Kovalenko V. NPP “MORION LTD.” Kiev.1030 p.

[18] Kitade, T., Odahara, Y., Shinohara, S., Ikeuchi, T., Sakai, T., Morikawa, K., Minamikawa, M., Toyota, S., Kawachi, A., and Hyodo, M. 1999. "Studies on the Enhanced Effect of Acupuncture Analgesia and Acupuncture Anesthesia by D-phenylalanine (2nd report)-Schedule of Administration and Clinical Effects in low Back Pain and Tooth Extraction." Acupunct. Electrother. Res. 15 (2): 121-35.

[19] Cheng, R., and Pomeranz, B. 1981. "Monoaminergic Mechanism of Electroacupuncture Analgesia." Brain Res. 215 (1-2): 77-92.

[20] Tortorici, V., and Vanegas, H. 2000. "Opioid Tolerance Induced by Metamizol (Dipyrone) Microinjections into the Periaqueductal Grey of Rats." Eur. J. Neurosci. 12 (11): 4074-80.

[21] Aguirre-Banuelos, P., and Granados-Soto, V. 1999. "Evidence for a Peripheral Mechanism of Action for the Potentiation of the Antinociceptive Effect of Morphine by Dipyrone." J. Pharmacol. Toxicol. Methods. 42 (2): 79-85.

[22] De Campos, D., Cunha, F., and Ferreira, S. 1988. "A New Mechanism of Action of Dipyrone: Blockade of the Release of a Nociceptive Factor from Macrophages." Braz. J. Med. Biol. Res. 1 (3): 565-8.

[23] Lorenzetti, B., and Ferreira, S. 1985. "Mode of Analgesic Action of Dipyrone: Direct Antagonism of Inflammatory Hyperalgesia." Eur. J. Pharmacol. 114 (3): 375-81.

[24] Frink, M., Hennies, H., Englberger, W., Haurand, M., and Wilffert, B. 1996. "Influence of Tramadol on Neurotransmitter Systems of the Rat Brain." Arzneimittel forschung 46 (11): 1029-36.

[25] Raffa, R., Friderichs, E., Reimann, W., Shank, R., Codd, E., and Vaught, J. 1992. "Opioid and Nonopioid Componrnts Independently Contribute to the Mechanism of Action of tramadol, an 'Atypical' Opioid Analgesic." J. Pharmacol. Exp. Ther. 260 (1): 275-85.

[26] Gulyar, S., and Tamarova, Z. 2017. "Analgesic Effects of the Polarized Red-Infrared LED Light." Journal of US-China Medical Science 14: 47-57.

[27] Gura, E., Bagatskaja, E., and Limansky, Y. 2001. "Investigation of the Mechanism of an Analgesia Induced by Irradiation of Microwaves of an Acupuncture Point of a Mice." In: Materials. Conf. Devoted to the 160-th Anniversary of the Nazis. Honey. University "History and 
Contemporary Achievements of Physiology in Ukraine”. Kyiv: 27-8. (in Ukrainian)

[28] Kulikovich, Y., and Tamarova, Z. 1999. "Rol of Opiatate Receptors in Analgesia, Caused by the Action of the Acupuncture Point by Low-Intensity Millimeter Waves." Journal Medical Projections 4 (3): 9-14.

[29] Limansky, Y., Gulyar, S., and Tamarova, Z. 2009. "BIOPTRON-induced Analgesia: 10. Involvement of Opioid-Ergicsysem in Analgetic Effect of Polarized Light on Antinocicepive Acupuncture Point." In Anthology of Light Therapy. Medical BIOPTRON Technologies. Kyiv: Bogomoletz Institute of Physiology at the National Academy of Sciences of Ukraine, 266-75. (in Russian)

[30] Ulett, G., Han, S., and Han, J. 1998. "Electroacupuncture: Mechanisms and Clinical Application.” Biol. Psychiatry 44 (2): 129-38.

[31] McCarson, K., and Goldstein, B. 1989. "Naloxone Blocks the Formalin-induced Increase of Substance $\mathrm{P}$ in the Dorsal Horn." Pain 38 (3): 339-45.

[32] Wang, Y., Wang, S., and Zhang, W. 1991. "Effects of Naloxone on the Changes of Pain Threshold and Contents of Monoamine Neurotransmitters in Rat Brain Induced by EA.” J. Tradit. Chin. Med. 11 (4): 286-90.

[33] He, X., Liu, X., Zhu, B., Xu, W., and Zhang, S. 1995. "Central Mechanism of an Extensive Analgesic Effect due to Strong Electroacupuncture of Acupoint on Spinal Dorsal Horn Neurons." Sheng Li Hsueh Pao 47 (6): 605-9.

[34] Gulyar, S., and Tamarova, Z. 2016. "Analgesic Effect of a Polychromatic Polarized Light in Combination with Nonsteroidal Anti-inflammatory Drugs.” IX Intern. simp. “Actual Problems of Biophysical Medicine”, 37-9.

[35] Adair, R. 1994. "Effects of Weak High-Frequency Electromagnetic Fields on Biological Systems." Plenum Press. New York, 207-21.

[36] Bernhardt, J., and Vogel, E. 1996. "Biophysical Interaction Mechanisms." In Proc. Internat, Workshop, 22-6.

[37] Chiabrera, A., Bianco, B., and Moggia, E. 1995. "Recent Advances in Biophysical Modelling of Radiofrequency
Electromagnetic Field Interactions with Living Systems.” In Proc. Wireless Technol. Res., 18-24.

[38] Menendez, R. 1999. "Three Molecular Mechanisms to Explain Some Biological Effects of Electromagnetic Fields and Hypogravity." Med. Hypotheses. 52 (3): 239-45.

[39] Robertson, B., and Astumian, R. 1992. "Interpretation of the Effect of an Oscillating Electric Field on Membrane Enzymes." Biochemistry 31 (1): 138-41.

[40] Weaver, J., Vaughan, T., Adair, R., and Astumian, R. 1998. "Theoretical Limits on the Threshold for the Response of Long Cells to Weak Extremely Low Frequency Electric Fields due to Ionic and Molecular Flux Rectification." Biophys. J. 75 (5): 2251-4.

[41] Rosen, A. 1994. "Threshold and Limits of Magnetic Field Action at the Presynaptic Membrane." Biochim. Biophys. Acta. 1193 (1): 62-6.

[42] Phillips, J. 1993. "Effects of Electromagnetic Field Exposure on Gene Transcription." J. Cell Biochem. 51 (4): 381-6.

[43] Luben, R. 1991. "Effects of Low-Energy Electromagnetic Fields (Pulsed and DC) on Membrane Signal Transduction Processes in Biological Systems." Health Phys. 61 (1): 15-28.

[44] Krause, D., Penafield, L., and Litovitz, T. 1997. "Role of Modulation on the Effect of Microwaves on Ornithine Decarboxylase Activity in L929 Cells." Bioelectromagnetics 18 (2): 132-41.

[45] Chiabrera, A., Bianco, B., Moggia, E., and Kaufman, J. 2000. "Zeeman-Stark Modeling of the RF EMF Interaction with Ligand Binding." Bioelectromagnetics 21 (4): 312-24.

[46] Goodman, E., Greenebaum, B., and Marron, M. 1995. "Effects of Electromagnetic Fields on Molecules and Cells." Int. Rev. Cytol. 158: 279-338.

[47] Kamedula, M., and Kamedula, T. 1996. "Combined Biological Effect of Electromagnetic Fields and Chemical Substances." Med. Pr. 47 (3): 285-92. 